\title{
Influence of gender and age on the survival of patients with nasopharyngeal carcinoma
}

\author{
Guangli Xiao*, Yabing Cao, Xibin Qiu, Weihua Wang and Yufeng Wang
}

\begin{abstract}
Background: The prognostic value of gender and age in the survival of nasopharyngeal carcinoma (NPC) patients treated with intensity-modulated radiotherapy (IMRT) is unclear. Several studies have suggested a female advantage in the prognosis of solid tumors. We investigated the relationship between gender differences and disease outcome in NPC patients treated with IMRT in South China.

Methods: A total of 299 patients with non-disseminated NPC were analyzed retrospectively. IMRT was delivered with a simultaneous modulated, accelerated radiotherapy boost technique at prescribed doses of $70 \mathrm{~Gy} / 30$ fractions/6 weeks to the primary tumor (GTVp) and positive neck nodes (GTVn), 60Gy (2.0 Gy/day) to the clinical target volume (CTV) and upper neck region and $54 \mathrm{~Gy}(1.8 \mathrm{~Gy} /$ day) to the clinically negative low neck. A median boost dose of $9.2 \mathrm{~Gy}$ (4-20 Gy) was administered to patients with persistent disease at the primary site.

Results: With a median follow-up of 52 months, the male patients had a significantly unfavorable 5-year OS (70.7\% compared to $94.1 \%, P<0.001)$, DPFS $(71.5 \%$ compared to $87.3 \%, P=0.029)$ and DMFS $(77.2 \%$ compared to $89.7 \%, P=0.036)$ than the female patients. In patients younger than 45 , the male patients had a poorer 5 -year OS (66.8\% compared to $91.2 \%, P=0.008)$, DPFS (59.9\% compared to $91.2 \%, P=0.005)$ and DMFS (66.4\% compared to $94.0 \%, P=0.004)$ than the female patients. For patients older than 45 , only the 5 -year OS ( $72.2 \%$ compared to $96.0 \%, P=0.001)$ was significantly different.
\end{abstract}

Conclusions: Gender and age are strong independent prognostic factors for NPC in this study. We are the first to report that younger male patients were more likely to have distant metastases and exhibited inferior overall survival and disease progression-free survival rates compared to other patients.

Keywords: NPC, Gender, Age and survival

\section{Background}

The epidemiology of nasopharyngeal carcinoma (NPC) shows a uniquely skewed geographic distribution. High incidence rates are observed in the southern part of China. According to the registry data from Macao in 2009, NPC was the fifth most common cancer in men and ninth most common cancer in women. The incidence and mortality rates of NPC were 15.5 and 11.3, respectively, for men per 100,000 people and 5.4 and 0.4, respectively, for women per 100,000 people. NPC was also the most common cancer in young male adults, accounting for $23 \%$ of all cancers in that age group [1]. It is unclear why male patients displayed higher morbidity and mortality. Many studies on the prognostic factors for NPC have been published. A

\footnotetext{
*Correspondence: xiaoglbj@aliyun.com

Radiation Therapy Center, Kiang Wu Hospital, Macao, China
}

major limitation of the previous studies examining the effect of gender and age is the lack of adequate adjustment for other relevant clinical prognostic factors. IMRT has been used in our center since 2003, and we have treated more than 400 patients with NPC using IMRT. In this article, we explore the prognostic factors associated with these patients.

\section{Methods \\ Patient characteristics}

Between December 2003 and November 2010, there were 314 consecutive, newly diagnosed NPC patients in our Hospital. Of these patients, 13 patients with distant metastases before treatment or within 3 months after the completion of radiation therapy were excluded, 1 patient was excluded for emotional reasons, and 1 patient who died 
from another disease during treatment was excluded. The remaining 299 patients were included in the present study.

There were $213(71.2 \%)$ male and 86 (28.8\%) female patients. The median age was 49 (range 18 to 83 ). According to the AJCC/UICC (7th edition) staging criteria, there were 8 patients $(2.7 \%)$ with stage I disease, 29 patients (9.7\%) with stage II disease, 190 patients (63.5\%) with stage III disease and 72 patients $(24.1 \%)$ with stage IV disease. Thus, a total of $262(87.6 \%)$ patients presented with stage III-IV cancer. All patients were histologically confirmed cases: there were 266 (89.0\%) undifferentiated carcinomas (Grade 4), 28 (9.4\%) poorly differentiated carcinomas (Grade 3) and 5 (1.7\%) moderately differentiated carcinomas (Grade 2).

\section{Radiotherapy}

All patients received an entire course using the intensity modulated radiotherapy technique (IMRT). The primary nasopharynx and the upper neck were treated with IMRT using coplanar beams. The lower neck and the supraclavicular fossae were irradiated with a single anterior field using conventional radiotherapy. The gross tumor volume (GTV) was defined as all gross disease detected by the imaging studies and physical examination and included the primary tumor (GTVp) and all enlarged neck nodes (GTVn). We designed two planning target volumes (PTV1 and PTV2). Planning target volume 1 (PTV1) encompassed the GTVp with a 5-10 mm margin and GTVn with a 2-3 $\mathrm{mm}$ margin of adjacent tissue, ensuring that the high-dose zone would irradiate the tumor. Planning target volume 2 (PTV2) consisted of the clinic target volume (CTV) and included the entire nasopharynx, retropharyngeal lymph node regions, parapharyngeal space, posterior nasal cavity, skull base, clivus, inferior sphenoid sinus and bilateral upper deep jugular nodes, with a margin to account for patient motion and setup error. If the level I area lymph node was involved or the bulky IIa lymph node was at presentation, the field was required to cover the level I area. The surrounding critical normal structures such as the brainstem, spinal cord, optic nerves, chiasm, lens, parotid glands, temporomandibular joints, temporal lobe, and inner ears were also outlined.

The prescribed dose for the GTV, PTV1 and PTV2 were $70 \mathrm{~Gy}, 66 \mathrm{~Gy}$ and $60 \mathrm{~Gy}$, respectively, to at least $95 \%$ volume of the targets in 30 fractions over 6 weeks. The anterior cervical photon field delivered 66 Gy to the visible neck nodes plus a $2 \mathrm{~mm}$ margin, as well as 54 Gy to the clinically negative nodal regions. Persistent disease in the primary site was given a median boost dose of 9.2 Gy (4-20 Gy) with IMRT or X-knife.

\section{Chemotherapy}

Concurrent chemoradiation was prescribed for 178 (59.5\%) patients with a heavy tumor burden, who were treated
Table 1 The characteristics and prognosis for male and female patients

\begin{tabular}{|c|c|c|c|}
\hline Variable & Men & Women & $P$ value \\
\hline Patient (\%) & $213(71.2)$ & $86(28.8)$ & \\
\hline Age (year) & $49(18-83)$ & $47(22-75)$ & 0.515 \\
\hline Chemotherapy & $123(57.7)$ & $52(60.5)$ & 0.835 \\
\hline \multicolumn{4}{|l|}{ Histologic type } \\
\hline $\begin{array}{l}\text { undifferentiated } \\
\text { carcinoma }\end{array}$ & $185(86.9)$ & $81(94.2)$ & 0.680 \\
\hline $\begin{array}{l}\text { poorly differentiated } \\
\text { carcinoma }\end{array}$ & $25(11.7)$ & $3(3.5)$ & \\
\hline $\begin{array}{l}\text { moderately } \\
\text { differentiated } \\
\text { carcinoma }\end{array}$ & $3(1.4)$ & $2(2.3)$ & \\
\hline $\begin{array}{l}\text { nasopharynx tumor } \\
\text { volume }\left(\mathrm{cm}^{2}\right) \text { (median) }\end{array}$ & $36.5(1.2-279.3)$ & $27.2(1.5-222.9)$ & 0.055 \\
\hline $\begin{array}{l}\text { Lymph node max } \\
\text { diameter (cm) (median) }\end{array}$ & $2.5(0.5-9.0)$ & $2(0.4-13.0)$ & 0.253 \\
\hline \multicolumn{4}{|l|}{ T stage } \\
\hline $\mathrm{T} 1$ & $22(10.3)$ & $11(12.8)$ & 0.563 \\
\hline $\mathrm{T} 2$ & $47(22.1)$ & $20(23.3)$ & \\
\hline T3 & $106(49.8)$ & $40(46.5)$ & \\
\hline T4 & $38(17.8)$ & $15(17.4)$ & \\
\hline \multicolumn{4}{|l|}{ N stage } \\
\hline No & $11(5.2)$ & $5(5.8)$ & 0.166 \\
\hline N1 & $37(17.4)$ & $22(25.6)$ & \\
\hline N2 & $145(68.1)$ & $53(61.6)$ & \\
\hline N3 & $20(9.4)$ & $6(7.0)$ & \\
\hline \multicolumn{4}{|l|}{ TNM stage } \\
\hline stage & $4(1.9)$ & $4(4.7)$ & 0.192 \\
\hline stage & $18(8.5)$ & $11(12.8)$ & \\
\hline stage & $139(65.3)$ & $51(59.3)$ & \\
\hline stage & $52(24.4)$ & $20(23.3)$ & \\
\hline Local failure (\%) & $13(6.1)$ & $5(5.8)$ & 0.924 \\
\hline Regional failure (\%) & $11(5.2)$ & $1(1.2)$ & 0.111 \\
\hline Distant metastasis (\%) & $45(21.1)$ & $10(11.6)$ & 0.055 \\
\hline Tumor progression (\%) & $57(26.8)$ & $14(16.3)$ & 0.054 \\
\hline $\begin{array}{l}\text { Median time to local } \\
\text { failure }(m)\end{array}$ & $22(9-93)$ & $49(10-96)$ & 0.017 \\
\hline $\begin{array}{l}\text { Median time to regional } \\
\text { failure }(\mathrm{m})\end{array}$ & $26(6-63)$ & 41 & 0.015 \\
\hline $\begin{array}{l}\text { Median time to distant } \\
\text { metastasis }(\mathrm{m})\end{array}$ & $19(5-78)$ & $23(7-73)$ & 0.020 \\
\hline $\begin{array}{l}\text { Median time to disease } \\
\text { progression }(\mathrm{m})\end{array}$ & $18(5-93)$ & $27.5(7-96)$ & 0.010 \\
\hline
\end{tabular}

with weekly cisplatin $\left(40 \mathrm{mg} / \mathrm{m}^{2}\right)$ during the course of RT. There were 21 patients who received neoadjuvant chemotherapy, such as cisplatin or carboplatin plus docetaxel, whereas 10 patients were given adjuvant chemotherapy 
because of a large tumor burden or a poor response to $\mathrm{RT}$. The decision to treat with chemotherapy was made by each patient's physician.

\section{Follow-up and statistical analysis}

The follow-up duration was calculated from the first date of treatment; the cut-off date was the end of March 2012 or the time of death. Among living patients, all had a follow-up time of at least 22 months.

The data were analyzed using the SPSS 17.0 statistical software package. Survival rates were estimated with the Kaplan-Meier method. Differences in survival curves between the subgroups were analyzed using the log-rank test. Multivariate analysis was performed using the Cox regression model. Correlation analysis was conducted using bivariate correlation.

\section{Results}

With a median follow-up of 52 months (range 5 to 99 months), there were 18 (6.0\%) patients who developed local failure, including 1 patient (3\%) with T1 stage, 3 patients (4.5\%) with T2 stage, 8 patients (5.5\%) with T3 stage and 6 patients (11.3\%) with T4 stage. The median time of local failure was 30 (9-96) months. There were 12 (4.0\%) patients who developed regional nodal failure. The median time of regional failure was 28 (6-63) months. Fifty-five (18.4\%) patients developed distant metastases. The median time of distant failure was 21 (5-78) months.

The gender ratio was balanced for age, disease staging, lymph node metastasis characteristics (tumor size, necrosis and extracapsular extension), treatment methods and radiation reaction. Although it seems that the proportion of advanced cases is higher in male than female patients, the difference is not statistically significant. The
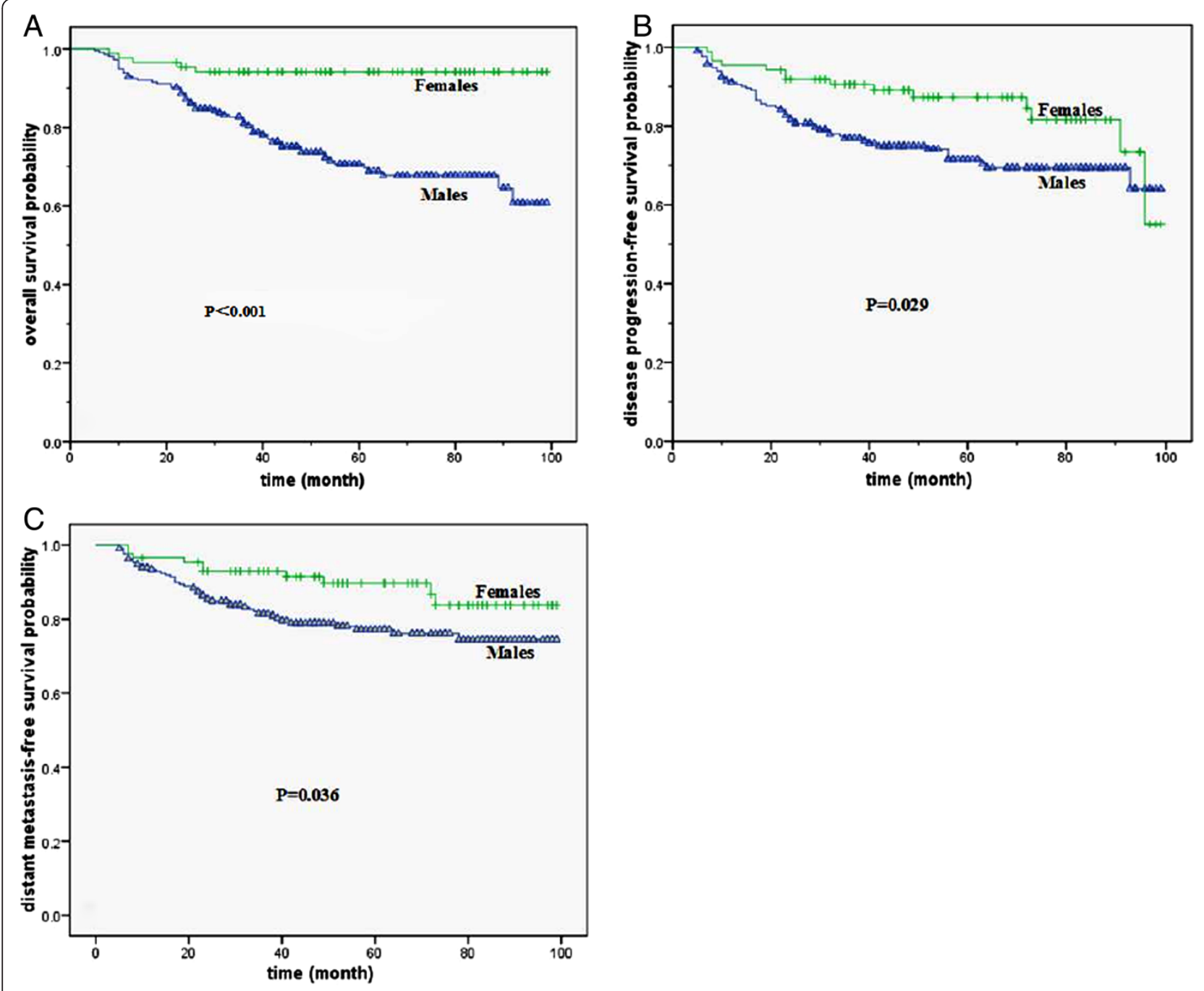

Figure 1 Survival curves for male and female patients. A. The overall survival curves of male and female. B. The disease progression-free survival curves of male and female. C. The distant metastasis-free survival curves of male and female. 
median time of therapeutic failure was significantly different between male and female patients (Table 1).

Of all the patients, the male patients had a significantly unfavorable 5-year overall survival (OS) (70.7\% compared to $\left.94.1 \%, \mathrm{P}<0.001, X^{2}=16.816\right)$, disease progression-free survival (DPFS) (71.5\% compared to $87.3 \%, P=0.029$, $\left.X^{2}=4.743\right)$ and distant metastasis-free survival (DMFS) (77.2\% compared to $89.7 \%, P=0.036, X^{2}=4.383$ ) compared to female patients (Figure 1). The number of local or regional failures was too small to allow meaningful analysis, and the 5-year local progression-free survival (LPFS) (92.9\% compared to $\left.95.6 \%, \mathrm{P}=0.684, X^{2}=0.165\right)$ and regional progression-free survival (RPFS) (93.6\% compared to $98.4 \%, \mathrm{P}=0.084, X^{2}=2.964$ ) were not different between genders.

For patients with stage I-II, stage III and stage IV cancers, the 5-year OS between male and female patients was $94.7 \%$ compared to $100 \%\left(\mathrm{P}=0.182, X^{2}=1.784\right)$, $77.8 \%$ compared to $96.1 \%\left(\mathrm{P}=0.009, X^{2}=6.916\right)$ and
$41.6 \%$ compared to $84.4 \%\left(\mathrm{P}=0.006, X^{2}=7.442\right)$, respectively. The differences in the 5-year DPFS and DMFS between male and female with stage I-II, stage III and stage IV were not significantly different: for DPFS the values were $100 \%$ compared to $100 \%, 73.6 \%$ compared to $89.1 \%\left(\mathrm{P}=0.170, X^{2}=1.885\right)$ and $51.7 \%$ compared to $72.2 \%\left(P=0.153, X^{2}=2.046\right)$, respectively for DMFS the values were $100 \%$ compared to $100 \%, 79.1 \%$ compared to $91.2 \%\left(\mathrm{P}=0.132, X^{2}=2.269\right)$ and $58.5 \%$ compared to $76.2 \%\left(P=0.232, X^{2}=1.430\right)$, respectively.

For patients younger than 45 , the male patients had a significantly unfavorable 5 -year OS than female patients (66.8\% compared to $91.2 \%, \mathrm{P}=0.008, X^{2}=7.067$ ), DPFS (59.9\% compared to $91.2 \%, \mathrm{P}=0.005, X^{2}=7.724$ ) and DMFS (66.4\% compared to $94.0 \%, \mathrm{P}=0.004, X^{2}=8.461$ ) (Figure 2). For patients older than 45, only the 5-year OS $\left(72.2 \%\right.$ compared to $\left.96.0 \%, \mathrm{P}=0.001, X^{2}=10.186\right)$ was significantly different. The 5-year DPFS (76.4\% compared to $\left.84.1 \%, \mathrm{P}=0.483, X^{2}=0.493\right)$ and DMFS $(81.5 \%$
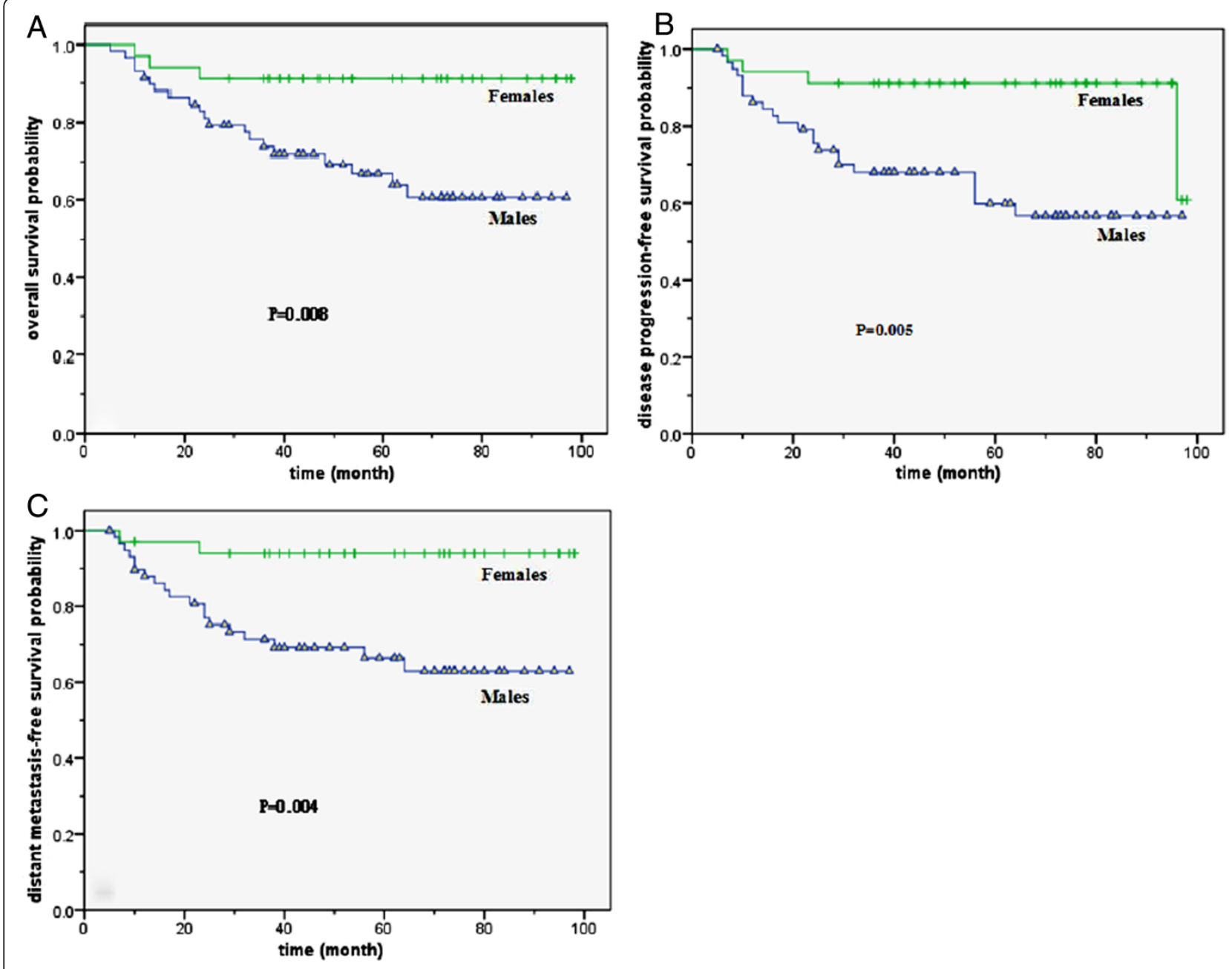

Figure $\mathbf{2}$ Survival curves for male and female patients younger than $\mathbf{4 5}$ years old. A. The overall survival curves of male and female. B. The disease progression-free survival curves of male and female. $\mathbf{C}$. The distant metastasis-free survival curves of male and female. 
compared to $86.3 \%, \mathrm{P}=0.677, X^{2}=0.174$ ) were not significantly different. Male patients younger than 45 had a lower 5-year DPFS (56.7\% compared to $76.4 \%, \mathrm{P}=0.038$, $\left.X^{2}=4.324\right)$ and DMFS $(62.9 \%$ compared to $84.5 \%$, $\left.\mathrm{P}=0.013, X^{2}=6.114\right)$ than older male patients. However, the gap of OS curves narrowed in both age groups for male patients. The survival difference was not statistically significant (Figure 3). In contrast, female patients showed no age-related differences for the 5-year DPFS (91.2\% compared to $\left.84.1 \%, \mathrm{P}=0.198, X^{2}=1.656\right)$, DMFS $(94.0 \% \mathrm{com}-$ pared to $\left.86.3 \%, P=0.161, X^{2}=1.969\right)$ and OS $(91.2 \%$ compared to $96.0 \%, \mathrm{P}=0.346, X^{2}=0.887$ ).

The chemotherapy, including concurrent chemoradiation, neoadjuvant chemotherapy and adjuvant chemotherapy, did not improve the local-regional control rate or the distant metastasis rate. Although the patients with stage T3-4 who received concurrent chemoradiation had a tendency to improve the local failure rate (8/141 compared to $6 / 58$ ), this was not a statistically significant difference.

The results of multivariate analysis on the prognostic factors are shown in Table 2. Gender and TNM stage, a measure of the extent of the disease, were independent prognostic factors on overall survival, disease progressionfree survival and distant metastasis-free survival. Poststyloid parapharyngeal invasion and intracranial invasion were significant prognostic variables affecting local progression-free survival, whereas supraclavicular lymph node metastasis and visualization of extracapsular extension of the lymph node were identified as the main prognostic factors of regional progression-free survival.

\section{Discussion}

To date, only a few studies have focused specifically on the prognostic impact of gender and age on NPC. In
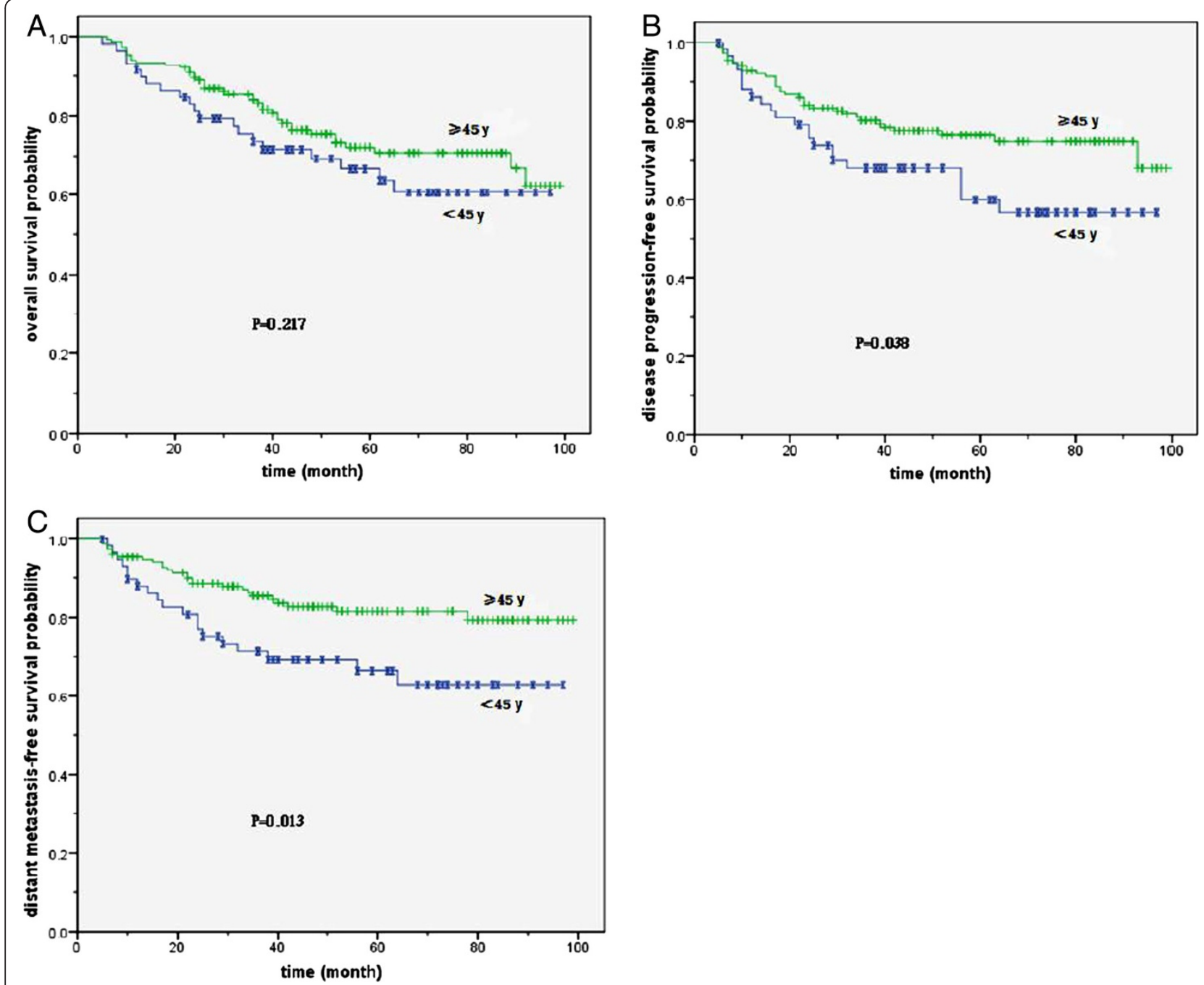

Figure 3 Survival curves for male patients in different age groups. A. The overall survival curves for male of different age groups. B. The disease progression-free survival curves for male of different age groups. C. The distant metastasis-free survival curves for male of different age groups. 
Table 2 Multivariate analysis on the prognostic factors of survival

\begin{tabular}{|c|c|c|c|c|c|c|}
\hline & & \multirow[t]{2}{*}{ RR } & \multicolumn{2}{|c|}{$95 \% \mathrm{Cl}$} & \multirow[t]{2}{*}{$P$} & \multirow[t]{2}{*}{$x^{2}$} \\
\hline & & & Lower & Upper & & \\
\hline \multirow[t]{5}{*}{ OS } & Sex (male or female) & 0.171 & 0.068 & 0.427 & 0.000 & 14.274 \\
\hline & TNM Stage & 1.915 & 1.125 & 3.260 & 0.017 & 5.723 \\
\hline & Intracranial invasion & 3.850 & 1.867 & 7.940 & 0.000 & 13.324 \\
\hline & Supraclavicular LNM & 2.458 & 1.149 & 5.257 & 0.020 & 5.375 \\
\hline & LN extracapsular extension & 3.183 & 1.854 & 5.464 & 0.000 & 17.642 \\
\hline \multirow[t]{4}{*}{ DPFS } & Sex (male or female) & 0.499 & 0.277 & 0.900 & 0.021 & 5.331 \\
\hline & TNM Stage & 2.320 & 1.530 & 3.517 & 0.000 & 15.702 \\
\hline & LN extracapsular extension & 2.411 & 1.419 & 4.099 & 0.001 & 10.573 \\
\hline & $\mathrm{LN}$ necrosis & 1.748 & 1.043 & 2.928 & 0.034 & 4.501 \\
\hline \multirow[t]{3}{*}{ DMFS } & Sex & 0.483 & 0.243 & 0.961 & 0.038 & 4.302 \\
\hline & TNM stage & 2.200 & 1.383 & 3.499 & 0.001 & 11.081 \\
\hline & LN extracapsular extension & 3.680 & 2.115 & 6.405 & 0.000 & 21.244 \\
\hline \multirow[t]{2}{*}{ LPFS } & Post-styloid Parapharyngeal invasion & 2.852 & 1.077 & 7.549 & 0.035 & 4.452 \\
\hline & Intracranial invasion & 5.316 & 1.613 & 17.521 & 0.006 & 7.536 \\
\hline \multirow[t]{2}{*}{ RPFS } & Supraclavicular LNM & 5.415 & 1.363 & 21.504 & 0.016 & 5.762 \\
\hline & LN extracapsular extension & 5.148 & 1.450 & 18.270 & 0.011 & 6.427 \\
\hline
\end{tabular}

$O S=$ overall survival, DPFS = disease progression-free survival, DMFS = distant metastasis-free survival, $L P F S=$ local progression-free survival, $R P F S=$ regional progression-free survival, $L N=$ lymph node, $L N M=$ lymph node metastasis.

addition, many reports studying the main impact of other prognostic factors have reported controversial results with regard to the prognostic impact of gender. Several larger Chinese studies [2-6] demonstrated that being female was a favorable factor for overall survival by multivariate analysis, although many studies found no significant difference in survival based on gender [7-9]. Some studies showed that gender affects other endpoints of prognostic analysis significantly, such as disease-free survival $[2,5,10]$, local control $[4,11,12]$, and distant metastasis $[2,3,11]$. Being male was an adverse prognostic factor in these studies.

We also found that male patients were more likely to have distant metastases than female patients and exhibited inferior overall survival and disease progression-free survival rates. Even in the subgroup analysis, similar results were obtained. The most intriguing result of our study was the male survival curves were consistently below female patients regardless of the statistical significance of the difference. If the sample size is big enough, maybe gender difference will become statistical significant for more end points. Furthermore, male patients exhibited a shorter interval before therapeutic failure compared to female patients. This suggests that a biological difference in tumor behavior exists between male and female patients. Gender differences in the incidence and prognosis of NPC may be due to genetic variants affected by the hormonal environment. Nasr [13] was the first to report on functional VEGF polymorphisms in patients with NPC in
2008. He found that men carrying the VEGF-2578 C allele had higher risk for NPC than women. Furthermore, there was a significant association between the distribution of the VEGF-2578 CC genotype among male patients and a larger tumor size and advanced cancer stage.

Most of the results studying the prognostic impact of age in NPC indicate that younger patients have a higher overall survival $[2,3,5,10,12]$. Some studies also showed that disease-related survival $[2,5,10,11]$, local control $[2,10]$ and distant metastasis [2] were affected by age. Only $\mathrm{Ma}$ [3] has reported that patients younger than 40 have lower OS and local control rates by multivariate analysis. However, these studies were not adjusted to account for other prognostic factors, such as tumor size, stage, therapeutic strategies and performance status. Because older patients were more likely to have comorbidities and a poorer performance status, which may contribute to a low tolerance for intense treatment (radiotherapy and/or chemotherapy), there were more non-tumor-related deaths in older patients. Moreover, the vast majority of previous studies employed conventional radiotherapy technology. The radiotherapy technique impacts the dose delivered to the local lesion and could pose a tolerance problem, affecting tumor control and survival in patients. Intensity-modulated radiotherapy offers the potential for improved treatment outcomes because patients, including older patients, have a high tolerance for the therapy. Furthermore, there were more opportunities to find differences in biological behavior between male and female 
patients due to the longer follow-up period. Our data showed that 5-year OS, DPFS and DMFS were more than $20 \%$ lower for male patients younger than 45 compared with female patients of the same age. Indeed, younger male patients had 20\% lower DPFS and DMFS values than older male patients. These data suggest that the variables of both gender and age must be considered important predictors for survival.

There are numerous reports concerning gender differences on the prognosis of other malignant tumors. An Asian population-based study observed that female patients display better survival rates for the majority of solid tumor sites, even after adjustment for age and stage. However, the survival gaps between male and female narrow as age increases [14]. Joosse [15] reported that the prognostic outlook for female patients compared to male patients with melanoma was equal in the 60-year-old age group, unlike the female patient advantage observed in the 45-year-old group, when examining the end points of relapse-free survival, time to lymph node metastasis, and time to distant metastasis. Wolf et al. [16] found that the favorable prognostic effect seen in female patients with small cell lung cancer was restricted to patients younger than 60 years old.

It is well known that sexual hormone levels begin to decrease on average at the age of forty to fifty years old and reach their lowest values at sixty years old. Some hypotheses concerning the cause of gender differences have not been confirmed, in part due to the particular focus placed on the effect of estrogen $[15,17,18]$. In fact, several preclinical studies had demonstrated that androgens can induce proliferative changes in cancer cell lines and promote tumorigenesis in animal models by androgens receptor (AR) [19,20] Maasberg et al. [21] (1989) found that application of testosterone resulted in a 3fold increase in cell proliferation in a cloning assay, whereas estrogen had no influence on tumor growth. This growth stimulation could be counteracted by the addition of anti-androgens such as cyproterone acetate or flutamide. These in vitro experiments imply that sexual hormones may play a role in the regulation of tumor growth. Our study demonstrated that being a younger male patient corresponded to a less favorable prognosis and suggested that male sexual hormones like androgens might drive tumor development in NPC.

The limitation of this paper is that it is a retrospective analysis. The underlying causes of the difference in the behavior of NPC between genders are not completely known. However, it is certain that male patients had a significantly unfavorable 5-year OS, DPFS and DMFS. In particular, younger male patients had more than $20 \%$ lower survival rates than female patients. Gender is a strong independent prognostic factor for NPC. Future work should focus on researching the mechanisms of gender difference in NPC progression and confirm the relationship between gender and genetic polymorphisms in experimental and clinical studies.

\section{Conclusion}

Gender and age are strong independent prognostic factors for NPC in this study. Younger men were more likely to have distant metastases and exhibited inferior overall survival and disease progression-free survival rates.

\section{Competing interests}

The authors declare that they have no competing interest.

\section{Authors' contributions}

All authors substantially contributed to the current manuscript as listed below. GX drafted the manuscript, is the principal investigator of the study and designed this study. The rest of the authors collected and reviewed data. All authors read and approved the final manuscript.

\section{Acknowledgements}

This study is supported by the Science and Technology Development Fund in Macao (No.069/2009/A3).

Received: 21 September 2012 Accepted: 29 April 2013

Published: 4 May 2013

\section{References}

1. The Health Bureau of the Macao Special Administrative Region Government: Annual report of Macao cancer registry; 2009. The electronic version of this article is the complete one and can be found online at: http://www.ssm.gov.mo/.

2. Lee AW, Sze WM, Au JS, Leung SF, Leung TW, Chua DT, Zee BC, Law SC, Teo PM, Tung SY, et al: Treatment results for nasopharyngeal carcinoma in the modern era: the Hong Kong experience. Int J Radiat Oncol Biol Phys 2005, 61(4):1107-1116.

3. Ma J, Mai HQ, Hong MH, Cui NJ, Lu TX, Lu LX, Mo HY, Min HQ: Is the 1997 AJCC staging system for nasopharyngeal carcinoma prognostically useful for Chinese patient populations? Int J Radiat Oncol Biol Phys 2001, 50(5):1181-1189.

4. Ng WT, Chan SH, Lee AW, Lau KY, Yau TK, Hung WM, Lee MC, Choi CW: Parapharyngeal extension of nasopharyngeal carcinoma: still a significant factor in era of modern radiotherapy? Int J Radiat Oncol Biol Phys 2008, 72(4):1082-1089.

5. Yeh SA, Tang Y, Lui CC, Huang YJ, Huang EY: Treatment outcomes and late complications of 849 patients with nasopharyngeal carcinoma treated with radiotherapy alone. Int J Radiat Oncol Biol Phys 2005, 62(3):672-679.

6. Yun-sheng G, Chao-su H, Hong-mei Y, Guo-pei Z, Lin K, Xia-yun H, Ting-ting $X$, Xiao-shen $W$, Jing $Y$, Su-qin $W$, et al: Treatment results of nasopharyngeal carcinoma : a retrospective analysis of 1837 cases in a single institute. Chinese J radiat oncol 2008, 17(5):5.

7. Chen CY, Han F, Zhao C, Lu LX, Sun Y, Liu XF, Lu TX: Treatment results and late complications of 556 patients with locally advanced nasopharyngeal carcinoma treated with radiotherapy alone. Br J Radio/ 2009, 82(978):452-458.

8. Chong Z, Wei-wei X, Fei H, Li-xia L, Shao-xiong W, Jian-zhou C, Cheng-guang L, Shao-min H, Xiao-wu D, Tai-xiang $L$, et al: Long-term outcome and prognostic factors of patients with nasopharyngeal carcinoma treated with intensity modulated radiation therapy. ONCOLOGY: CHINESE JOURNAL OF RADIATION; 2010:19(3).

9. Jian-ji P, Yu Z, Shao-jun L, Ling Y, Lu-ying X, Chuan-ben C, Cai-zhu P: Longterm results of nasopharyngeal carcinoma treated with radiotherapy: 1706 cases report. Chinese j radiat oncol 2008, 17(4):5

10. Yi JL, Gao L, Huang XD, Li SY, Luo JW, Cai WM, Xiao JP, Xu GZ: Nasopharyngeal carcinoma treated by radical radiotherapy alone: tenyear experience of a single institution. Int J Radiat Oncol Biol Phys 2006, 65(1):161-168.

11. Lai SZ, Li WF, Chen L, Luo W, Chen YY, Liu LZ, Sun Y, Lin AH, Liu MZ, Ma J: How does intensity-modulated radiotherapy versus conventional twodimensional radiotherapy influence the treatment results in 
nasopharyngeal carcinoma patients? Int I Radiat Oncol Biol Phys 2011, 80(3):661-668.

12. Liu X, Luo W, Liu M, Ye L, Sun Y, Xia Y: Treatment results and prognostic analysis of 1093 primary nasopharyngeal carcinoma: the experience of a single institution of Guangzhou in the beginning of the 21st century. Chin-Ger J Clin Oncol 2008, 7(4):187-195.

13. Nasr HB, Chahed K, Bouaouina N, Chouchane L: Functional vascular endothelial growth factor $-2578 \mathrm{C} / \mathrm{A}$ polymorphism in relation to nasopharyngeal carcinoma risk and tumor progression. Clin chim acta int $j$ clin chem 2008, 395(1-2):124-129.

14. Jung KW, Park S, Shin A, Oh CM, Kong HJ, Jun JK, Won JK: Do female cancer patients display better survival rates compared with males? analysis of the Korean national registry data, 2005-2009. PLoS One 2012, 7(12):e52457. www.plosone.org.

15. Joosse A, Collette S, Suciu S, Nijsten T, Lejeune F, Kleeberg UR, Coebergh JWW, Eggermont AMM, Vries E: Superior outcome of women with stage I/II cutaneous melanoma: pooled analysis of four European organisation for research and treatment of cancer phase III trials. J Clin Oncol 2012, 30(18):2240-2247.

16. Wolf M, Holle R, Hans K, Drings P, Havemann K: Analysis of prognostic factors in 766 patients with small cell lung cancer (SCLC): the role of sex as a predictor for survival. $\mathrm{Br} J$ Cancer 1991, 63:986-992.

17. Gupta A, Driscoll MS: Do hormones influence melanoma? Facts and controversies. Clin Dermatol 2010, 28:287-292.

18. Lens $\mathrm{M}$, Bataille V: Melanoma in relation to reproductive and hormonal factors in women: current review on controversial issues. Cancer Causes Contr 2008, 19:437-442.

19. Garay JP, Karakas B, Abukhdeir AM, Cosgrove DP, Gustin JP, Higgins MJ, Konishi H, Konishi Y, Lauring J, Mohseni M, et al: The growth response to androgen receptor signaling in ERa-negative human breast cells is dependent on p21 and mediated by MAPK activation. Breast Cancer Res 2012, 14:R27. doi:10.1186/bcr3112.

20. Gucalp A, Traina TA: Triple-negative breast cancer: role of the androgen receptor. Cancer J 2010, 16:62-65.

21. Maasberg M, Jaques G, Rotsch M, Enderle-Schmidt U, Weehle R, Havemann K Androgen receptors, androgen dependent proliferation, and 5-reductase activity of small cell lung cancer cell lines. Int J Cancer 1989, 43:685-691.

doi:10.1186/1471-2407-13-226

Cite this article as: Xiao et al.: Influence of gender and age on the survival of patients with nasopharyngeal carcinoma. BMC Cancer 2013 13:226.

\section{Submit your next manuscript to BioMed Central and take full advantage of:}

- Convenient online submission

- Thorough peer review

- No space constraints or color figure charges

- Immediate publication on acceptance

- Inclusion in PubMed, CAS, Scopus and Google Scholar

- Research which is freely available for redistribution 